\title{
Dog bites: how big a problem?
}

\author{
Jeffrey J Sacks, Marcie-jo Kresnow, Barbara Houston
}

Abstract

Objective-To estimate the magnitude of the dog bite problem in the US.

Methods-Data on dog bites were gathered as part of a 1994 national telephone survey of 5238 randomly dialed households. Data were weighted to provide national estimates.

Results-The weighted total number of dog bites was 4494083 (estimated incidence $=18 / 1000$ population); of these, 756701 persons sustained bites necessitating medical attention (incidence rate $=3 / 1000$ ). Children had $3 \cdot 2$ times higher medically attended bite rates than adults (6.4/1000 children $v 2 / 1000$ adults).

Conclusions-More attention and research needs to be devoted to the prevention of $\mathrm{dog}$ bites. Potential prevention strategies include: educational programs on canine, behavior, especially directed at children; laws for regulating dangerous or vicious dogs; enhanced animal control programs; and educational programs regarding responsible dog ownership and training. Unfortunately, the relative or absolute effectiveness of any of these strategies has not been assessed. Continuing surveillance for dog bites will be needed if we are to better understand how to reduce the incidence of dog bites and evaluate prevention efforts.

(Injury Prevention 1996; 2: 52-54)

Keywords: dog bites, surveillance, telephone survey.

In 1986, a special survey determined that dog bites caused 585000 injuries resulting in medical attention or restricted activity, an estimate that placed dog bites among the top 12 causes of non-fatal injury in the US. ${ }^{1}$ Animal bites are dealt with at the local geopolitical level and reports are not forwarded to the federal government, consequently there is no ongoing national surveillance system for non-fatal dog bites in the US. The 1986 survey was the most recent estimate of the magnitude of the problem. Because many non-fatal injury problems in the US lack a surveillance system, in 1994 the Centers for Disease Control and Prevention conducted the Injury Control and Risk Survey (ICARIS). ICARIS is a national survey designed to assess a wide variety of injury risk factors and injuries. This report summarizes data from that survey about dog bites.

\section{Methods}

ICARIS is a random digit dialing telephone survey that was conducted from 28 April-18
September 1994. Because there are racial differences in injury rates, ${ }^{23}$ telephone exchanges from all 50 states and the District of Columbia contained in a proprietary database were stratified by whether they had $\geqslant 10 \%$ of households occupied by minorities. Such exchanges were sampled at a higher rate than the remaining exchanges to improve the sample size and, therefore, precision of minority group specific estimates. At least six attempts were made to contact each number.

Because injury rates also differ by gender, ${ }^{3}$ we sought to ensure an equal gender balance of respondents to improve the precision of gender specific estimates. Once a household was reached, we determined the number of adult (aged 18 years and older) men and women in each. We then randomly selected one gender from those in the household; if more than one eligible individual was in the gender category, we asked for the individual with the most recent birthday. After giving consent for the interview, an English or Spanish speaking adult respondent enumerated the age and sex of children aged $<15$ years in the household. We gathered data on whether the adult respondent and each child had been bitten by a dog in the 12 months before interview and, if so, whether they had gone to an emergency department, doctor's office, or other place for medical care for the bite.

In view of the sampling strategy, that is, oversampling minorities and equalizing the respondent gender balance, the data required weighting to be representative of the US population. These weights include both a selection probability weight and a poststratification weight. Selection probability weights adjust for the probability of selecting a particular household and respondent. Poststratification weights scale up the weights of individual records to fully represent similar age, sex, and race group individuals in the same census region and metropolitan statistical area.

We used special survey data analysis software that accounts for the complex survey design to generate weighted estimates and $95 \%$ confidence intervals (CIs). ${ }^{4}$ The log-likelihood $\chi^{2}$ test was used to assess independence, and the adjusted Wald $F$ test to assess linear trends.

\section{Results}

The survey resulted in 5328 completed adult interviews (response rate ${ }^{5}=56 \cdot 1 \%$ ), representing a total of 3541 children aged $0-14$ years. Dog bites were reported for 94 adults and 92 children; of these, medical treatment was sought for 12 adults and 26 children. The weighted total of dog bites was 4494083 for an incidence rate of $18 / 1000$ population. An estimated 379320 adults (incidence $=2 / 1000$; $95 \% \mathrm{CI}=0.7$ to 3.3 ) and 377381 children 
Estimated number of dog bites and incidence rate, by age and sex of victim, ICARIS, US, 1994

\begin{tabular}{|c|c|c|c|c|}
\hline Characteristic & $\underset{\text { size }}{\text { Sample }}$ & $\begin{array}{l}\text { No } \\
\text { bitten }\end{array}$ & $\begin{array}{l}\text { Weighted } \\
\text { No bitten } \dagger\end{array}$ & $\begin{array}{l}\text { Incidence ratel } \\
1000(95 \% \mathrm{CI}) \ddagger\end{array}$ \\
\hline $\begin{array}{l}\text { Adults } \\
\text { Sex }\end{array}$ & 5236 & 94 & 3050992 & $16 \cdot 1(12 \cdot 1$ to $20 \cdot 0)$ \\
\hline $\begin{array}{l}\text { Male } \\
\text { Female }\end{array}$ & $\begin{array}{l}2682 \\
2554\end{array}$ & $\begin{array}{l}63 \\
31\end{array}$ & $\begin{array}{l}1944052 \\
1106940\end{array}$ & $\begin{array}{l}21.3(14.9 \text { to } 27.7) \\
11.2(6.6 \text { to } 15.9)\end{array}$ \\
\hline $\begin{array}{l}\text { Age (years) } \\
18-24\end{array}$ & & & & \\
\hline $\begin{array}{l}18-24 \\
25-34 \\
35-44 \\
\geqslant 45\end{array}$ & $\begin{array}{r}599 \\
1308 \\
1188 \\
2073\end{array}$ & $\begin{array}{l}19 \\
32 \\
23 \\
20\end{array}$ & $\begin{array}{l}730630 \\
846444 \\
840721 \\
633197\end{array}$ & $\begin{array}{l}29.3(13.3 \text { to } 45.3) \\
19.7(11.6 \text { to } 27.9) \\
21.2(10.8 \text { to } 31.6) \\
7.9(4.0 \text { to } 11.8)\end{array}$ \\
\hline $\begin{array}{l}\text { Children } \\
\text { Sex }\end{array}$ & 3537 & 92 & 1443091 & $24.5(18.2$ to 30.8$)$ \\
\hline $\begin{array}{l}\text { Male } \\
\text { Female } \\
\text { Age (years) }\end{array}$ & $\begin{array}{l}1825 \\
1685\end{array}$ & $\begin{array}{l}58 \\
34\end{array}$ & $\begin{array}{l}874020 \\
569071\end{array}$ & $\begin{array}{l}29.2(20.4 \text { to } 38.0) \\
20.0(11.0 \text { to } 28.9)\end{array}$ \\
\hline $\begin{array}{l}0-4 \\
5-9 \\
10-14\end{array}$ & $\begin{array}{l}1158 \\
1190 \\
1152\end{array}$ & $\begin{array}{l}30 \\
36 \\
26\end{array}$ & $\begin{array}{l}503694 \\
542074 \\
397323\end{array}$ & $\begin{array}{l}24.9(14.2 \text { to } 35.5) \\
28.4(17.0 \text { to } 39.7) \\
21.0(12.3 \text { to } 29.6)\end{array}$ \\
\hline
\end{tabular}

*Unweighted numbers; bite status unknown for two adults and four children; 68 adults missing age, 27 children missing sex, and 37 children missing age. $+W$ eighted national estimate. $¥ W$ eighted incidence rate and $95 \% \mathrm{CI}$; coefficients of variation range from $12-28 \%$.

(incidence $=6 \cdot 4 / 1000 ; 95 \% \mathrm{CI}=3.6$ to $9 \cdot 2$ ) sustained bites necessitating medical attention. A higher proportion of dog bites among children resulted in medical care than among adults $(26.4 \% v 12.4 \%)$. Among adults, males were more likely to be bitten than females $(p<0.02$; table). The incidence of bites decreased with increasing age $(p<0.01)$ and increased with increasing educational attainment $(p<0.01)$. Among children, neither age group nor sex was significantly associated with bite rates. Other variables examined (census region, urbanicity, race/ethnic group, and household income) were also not associated with bite rates for adults or children.

\section{Discussion}

Each year, an estimated $1.8 \%$ of the US population is bitten by a dog and $0.3 \%$ of the US population seeks care for a bite, that is 4.49 million bites, of which 756701 result in medical attention. Because of coverage of older teenagers by other risk factor surveys, ${ }^{6}$ we elected not to include persons aged $15-17$ years in ICARIS; thus, our estimates do not include the 10.8 million persons in this age group. We estimate that had we included them in the survey, we would have detected an additional 215600 bites, 43000 requiring medical care.

The $150 \%$ higher bite rate and $300 \%$ higher medically attended bite rate in children relative to adults is not unexpected. Children's small size may encourage a dog to act dominantly towards them. Many children's lack of judgment about how to deal with a dog, and their inability to fend off an attack, may put them at additional risk. A survey of 3238 Pennsylvania schoolchildren determined that by 12 th grade, $46 \%$ of students had been bitten, and $17 \%$ of students had received medical attention for a dog bite. ${ }^{7}$ Children are frequently bitten on the face $^{8}$ and any bite can result in severe lacerations, ${ }^{8}$ infection, ${ }^{9}$ or disability. ${ }^{10}$ Studies outside the US have also found that children ${ }^{11-14}$ and males ${ }^{11} 12$ are at higher risk of dog bite.

Our study has limitations. The data are self reported and unvalidated and the response rate was only $56 \%$. In addition, respondents were asked about bites occurring over a one year period, a relatively long time for recall. Bites resulting in medical attention are probably better recalled than less severe bites and may be less subject to recall problems. Studies in other developed nations have reported medically attended bite rates similar to what we found. ${ }^{11} 1215$ In many countries, management of dog bites includes rabies prophylaxis. This cost, and costs from wound management, antibiotic, and tetanus prophylaxis can result in a substantial health care burden. These costs further underscore the need for more attention to, and research on, the prevention of dog bites.

About $35 \%$ of American households owned a dog in 1994 - a total dog population of over 52 million. ${ }^{16}$ Studies have suggested that owners, through their selection and treatment of a pet, may be able to reduce the likelihood of owning a dog that will eventually bite. ${ }^{17}$ Other potential prevention strategies include: educational programs on canine behavior, especially directed at children, laws for regulating dangerous or vicious dogs, enhanced animal control programs, and educational programs regarding responsible dog ownership and training. Unfortunately, the relative or absolute effectiveness of any of these strategies has not been assessed.

Continuing surveillance for dog bites will be needed if we are to better understand how to reduce the incidence of dog bites and evaluate prevention efforts. While there is a system of national surveillance for fatal dog bites in the US (which reveals about 20 deaths each year attributable to dog bites), ${ }^{18}$ as can be seen from the ICARIS data, the non-fatal dog bite problem is five orders of magnitude greater. Thus, the death certification system is not adequate for monitoring the problem. Surveillance using official local reports, for example, to animal control or the health department, is problematic in that the majority of dog bites are not reported to official agencies, either in the US or abroad. ${ }^{71315}$ Surveillance via the health care delivery system appears possible, especially in areas where there are few sources of care. Because of problems getting providers to report legally notifiable conditions, it may be advisable to conduct medical record or log reviews to validate the sensitivity of such a surveillance procedure. Another option is periodic surveys of the population, whether by telephone or door-to-door. ${ }^{13}$ Whatever surveillance method chosen, it appears that dog bites merit far more attention as a remediable public health problem.

The following are members of the ICARIS project: principal investigator: Jeffrey J Sacks, MD, MPH. Project core group: investigator: Jeffrey J Sacks, MD, MPH. Project core group: Barbara Houston; Marcie-jo Kresnow, MS; Joann M O'Neil,
BA; and Suzanne M Smith MD, MPH, of NCIPC. James BA; and Suzanne M Smith MD, MPH, of NCIPC. James
Hersey, PhD; Rick Williams, PhD; and Aiman Zeid, MS, of Hersey, PhD; Rick Williams, PhD; and Aiman Zeid, MS, of Battelle. Sherry Marcy, MPH and Deborah J Zivan, BA of DataStat. Project associates: Christine M Branche-Dorsey,
PhD; Peter Briss MD; Terence Chorba, MD, MPH; Alex PhD; Peter Briss MD; Terence Chorba, MD, MPH; Alex
Crosby, MD, MPH; Yvette Davis, VMD, MPH; Jennifer Crosby, MD, MPH; Yvette Davis, VMD, MPH; Jennifer
Friday, PhD; Arlene Greenspan, Dr PH, PT; James Mercy, Friday, PhD; Arlene Greenspan, Dr PH, PT; James Mercy,
PhD; Phil McClain, MS; Julie Russell, PhD; Lloyd Potter, PhD, MPH; and Kenneth E Powell, MD, MPH, of NCIPC. Thomas Matte, MD, MPH, of National Center for Environmental Health. 
1 Sosin DM, Sacks JJ, Sattin RW. Causes of nonfatal injuries in the United States, 1986. Accid Anal Prev 1992; 24: $685-7$

2 Gulaid JA, Onwuachi-Saunders EC, Sacks JJ, Roberts DR. Differences in death rates due to injury among blacks and whites, 1984. MMWR 1988; 37: (No SS-3): 25-32. (CDC surveillance summaries, July 1988.)

3 Baker SP, O'Neill B, Ginsburg MJ, Li G. The injury fact book. 2nd Ed. New York: Oxford University Press, 1992

4 Shah BV SUDAAN survey data analysis software. Release 6.34. Research Triangle Park: Research Triangle Park Institute, September 1993

5 Council of American Survey and Research Organizations Task Force. On the definition of response rates. Port Jefferson, NY: Council of American Survey and Research Organisations, June 1982

6 Kann L, Warren CW, Harris WA, et al. Youth Risk Behavior Surveillance, United States, 1993. MMWR 1995; 44 (No SS-1). (CDC surveillance summaries, March 24, 1995.

7 Beck AM, Jones BA. Unreported dog bites in children. Public Health Rep 1985; 100: 315-21.

$8 \mathrm{Karlson}$ TA. The incidence of facial injuries from dog bites. fAMA 1984; 251: 3265-7.

9 Kizer KW. Epidemiologic and clinical aspects of animal bite injuries. $\mathcal{F A C E P} 1979 ; 8: 134-41$

10 Berzon DR, DeHoff JB. Medical costs and other aspects of dog bites in Baltimore. Public Health Rep 1974; 89: 377-81.

11 Thomas HF, Voss S. A survey of dog bites in Salisbury. $\mathscr{F} R$ Soc Health 1991; 111: 224-5.

2 Langley $\mathrm{T}$. The incidence of dog bites in New Zealand. NZ Med f 1992; 105: 33-5.

13 Eng TR, Fishbein DB, Talamante HE, et al. Urban epizootic of rabies in Mexico: epidemiology and impact of animal bite injuries. Bull World Health Organ 1993; 71: 615-24.

14 Lap YY. 5 year statistics of animal and insect bites in Hong Kong. ҰR Soc Health 1992; 112: 12-4.

15 ChomelBB, Trotignon J Epidemiolog cat bites in the Lyon area, France. Eur 7 Epidemiol 1992; 8: $619-24$.

16 Wise JK, Yang J-J. Dog and cat ownership, 1991-1998. $\mathcal{f}$ Am Vet Med Assoc 1994; 204: 1166-7.

17 Gershman KA, Sacks JJ, Wright JC. Which dogs bite? A case-control study of risk factors. Pediatrics 1994; 93: 913-7.

18 Sacks JJ, Sattin RW, Bonzo SE. Dog bite-related fatalitie from 1979 through 1988. $\mathcal{f} A M A$ 1989; 262: 1489-92.

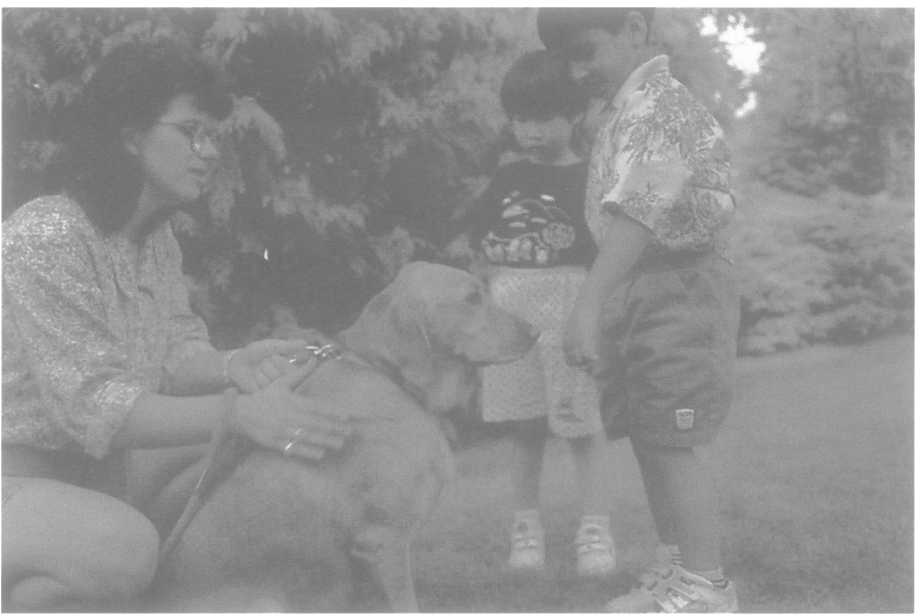

Teaching children how to meet a dog safely. (Thanks to the British Columbia Humane Education Society for providing the picture.) 